\title{
LAB 3 CLEANROOM FAN AND FILTERS ANALYSIS FOR THE SUPPORTS
}

D-ZERO ENGINEERING NOTE \# 3823.113 EN-492

Author: Herman Cease, PPD/ETT/D-Zero Mech. May 8, 1998

Approved By:

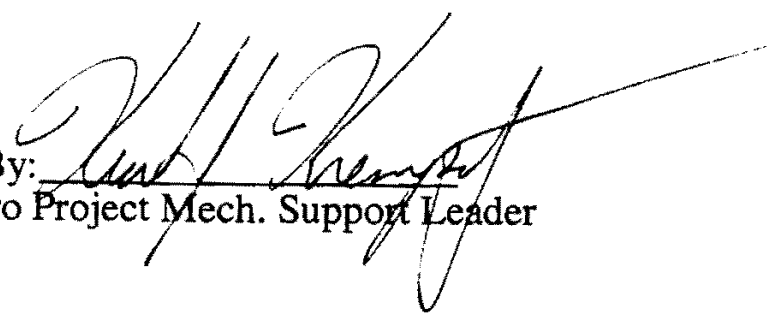




\section{Summary:}

A $1400 \mathrm{lb}$ blower fan and a $2700 \mathrm{lb}$ filter box are to be supported at Lab 3 . The support structure is a framework that suspends from the building wall to the cleanroom and to a washroom. The framework is made of welded 4 " $\times 8$ " $\times 1 / 4$ " rectangular A36 steel tube. Welds are to be standard prequalified welds as by AISC. The main support frame is approximately $7^{\prime}$ off the floor and welded onto the top of 10 columns. A deflection and stress study was performed on the planned structure.

A scaled plan view is given in drawing 3823.113-MD-358764. The heaviest loaded beams were labeled with a letter designation and were studied for beam deflections and stresses. The 4"x8" rectangular tube was also used for the substructure for the fan and filter mounts and to support a temporary floor grating during maintenance.

\section{Analysis:}

All material used was 4" $\mathrm{x} 8$ " $\mathrm{x} 1 / 4$ " rectangular steel tube. Assuming the member was used with 8 " as the beam height. Beam member data is given:

$$
\begin{aligned}
& \mathrm{I}=\mathrm{bh}^{3} / 12=4 \mathrm{inx} 8 \mathrm{in}^{3} / 12-3.5 \mathrm{in} \times 7.5 \mathrm{in}^{3} / 12=47.6 \mathrm{in}^{4} \\
& Z=I / y=47.6 \mathrm{in}^{4} / 4 \mathrm{in}=11.9 \mathrm{in}^{3} \\
& E=30,000,000 \mathrm{psi} \\
& E I=1.4 \mathrm{e} 9 \mathrm{lb} \mathrm{in}^{2} \\
& \text { The beams are assumed to be simply supported. }
\end{aligned}
$$

\section{Beams A \& B loading conditions:}

$1=186^{\prime \prime}$ span

$\mathrm{w}_{\text {self }}=300 \mathrm{lbs}$ uniformly loaded over the beam

$\mathrm{w}_{\text {filter }}=1350 \mathrm{lbs}$ point load @ 120" from one end. Filter weight assumed to be shared between beams A and B

$\mathrm{W}_{\text {walkaway\&subframes }}=400 \mathrm{lbs}$ centered $(800 \mathrm{lb}$ total shared between beams $\mathrm{A}$ and $B$ )

\section{Beams A \& B Analysis:}

Deflections and stresses due to self weight:

$$
\begin{aligned}
& \delta_{\text {self }}=5 \mathrm{wl} l^{3} / 384 \mathrm{EI}=5 \times 300 \mathrm{lb} \times 186 \mathrm{in}^{3} / 384 \times 1.4 \mathrm{e} 9 \mathrm{lb} \mathrm{in}^{2}=0.018 " \\
& \sigma_{\text {self }}=-\mathrm{wl} / 8 \mathrm{Z}=-300 \mathrm{lb} \times 186 \mathrm{in} / 8 \times 11.9 \mathrm{in}^{3}=-586 \mathrm{psi}
\end{aligned}
$$

Deflections and stresses due to filter weight @ 66" from one end:

The deflection of the beam at the filter location is

$$
\begin{aligned}
\delta_{\text {filter@70" }} & =\mathrm{wa}^{2} \mathrm{~b}^{2} / 3 \mathrm{EIL} \\
& =1350 \mathrm{lbx} 120^{2} \text { in } \times 66^{2} \mathrm{in} / 3 \times 1.4 \mathrm{e} 9 \mathrm{lb} \mathrm{in}{ }^{2} \times 186 \mathrm{in}=0.108^{\prime \prime} \\
\sigma_{\text {filter }}= & -\mathrm{wab} / 4 \mathrm{Zl} \\
& =-1350 \mathrm{lb} \times 120 \mathrm{in} \times 66 \mathrm{in} / 4 \times 11.9 \mathrm{in}^{3} \times 186 \mathrm{in}=-1207 \mathrm{psi}
\end{aligned}
$$


Deflections and stresses due to subframework for filter:

$$
\begin{aligned}
& \delta_{\text {subframework }}=\mathrm{wl}^{3} / 48 \mathrm{EI}=400 \mathrm{lb} \times 186^{3} \mathrm{in} / 48 \times 1.4 \mathrm{e} 9 \mathrm{lb} \mathrm{in}^{2}=0.038^{\prime \prime} \\
& \sigma_{\text {subframework }}=-\mathrm{wl} / 4 \mathrm{Z}=-400 \mathrm{lb} \times 186 \mathrm{in} / 4 \times 11.9 \mathrm{in}^{3}=-1563 \mathrm{psi}
\end{aligned}
$$

The maximum deflection and stress beams A or B:

Total $\delta=0.164 "$

Total $\sigma=-3356 \mathrm{psi}$

\section{Beam C loading conditions:}

1 - 186" span

$w_{\text {self }}=300$ lbs uniformly loaded over the length of the beam

$\mathrm{w}_{\mathrm{fan}}=700 \mathrm{lbs} @ 114$ " from one end. Fan weight assumed to be shared between beams $\mathrm{C}$ and $\mathrm{E}$

$\mathrm{W}_{\text {walkaway \& subframes }}=400$ lbs centered

\section{Beam C Analysis:}

Beam $\mathrm{C}$ is loaded less than beam $\mathrm{A}$ or $\mathrm{B}$ therefore making it conservative to use the results from beam $A$ or $B$.

\section{Beams D loading conditions:}

$1=92 "$ span

$\mathrm{w}_{\text {self }}=230 \mathrm{lbs}$

$w_{\text {fan }}=700 \mathrm{lbs} @ 63$ " from one end. Fan weight assumed to be shared between the two beams

$\mathrm{w}_{\text {walkaway\&subframes }}=400 \mathrm{lbs}$ uniformly loaded over the length $(800 \mathrm{lb}$ total shared weight)

\section{Beams D analysis:}

Beam D is loaded less and is shorter than beams $\mathrm{A}, \mathrm{B}$ or $\mathrm{C}$, therefore making it conservative to use the results from beams $\mathrm{A}, \mathrm{B}$ or $\mathrm{C}$.

\section{Beam E Analysis:}

Beam $E$ is not as heavily loaded as the other beams so it is conservative to use the results from beam $D$ for this member.

\section{Critical buckling load for the columns:}

The column height is 84 inches.

It is assumed the columns are rigidly mounted to the floor.

Here $I$ is calculated with 4 inches as the beam height

$$
\begin{aligned}
& I=\mathrm{bh}^{3} / 12 \\
& I=8 \times 4^{3} / 12-7.5 \times 3.5^{3} / 12=15.8 \mathrm{in}^{4}
\end{aligned}
$$




$$
P_{\text {critical }}=\pi^{2} \mathrm{IE} / 4 \mathrm{~L}^{2}=\pi^{2} \times 15.8 \times 30 \mathrm{e} 6 / 4 \times 84^{2}=16,000 \mathrm{lbs}
$$

One column could conservatively support the entire weight of the support structure without collapsing.

\section{Conclusions:}

The $1400 \mathrm{lb}$ blower fan and the $2700 \mathrm{lb}$ filter box are supported by a welded structure at Lab 3. The structure is made of 4" $\times 8^{\prime \prime} \times 1 / 4$ " A36 box with a yield strength of 36,000 psi. The maximum bending stress allowed is $0.66 \mathrm{x}$ Yield $=$ 23,760 psi as by AISC. All stresses in the structure are conservatively below the maximum allowable stresses.

When maintenance is performed on the fans and filters, the area below the support frame will be temporarily roped off to prevent access in the area under the structure. 


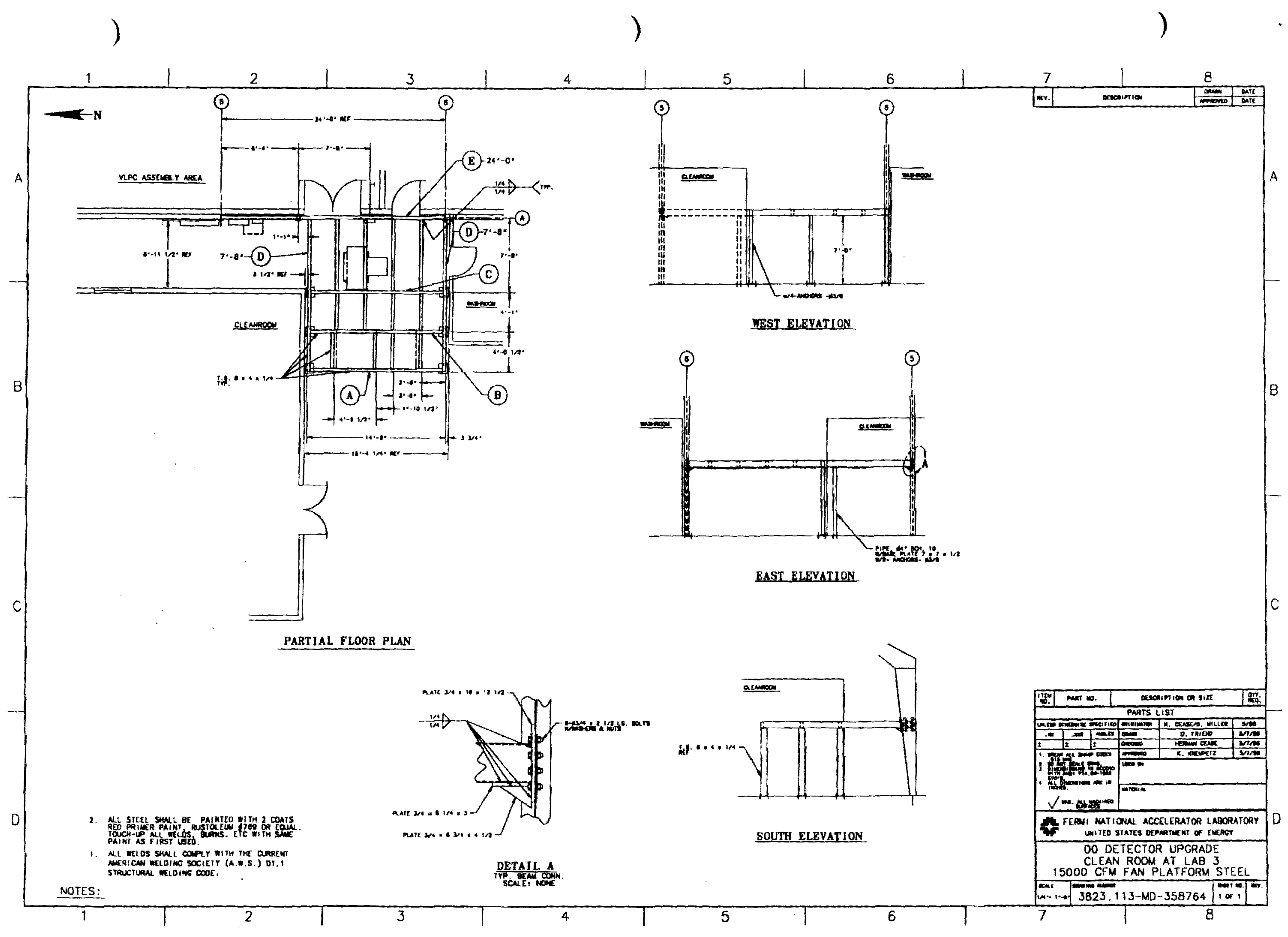

